\title{
Radiographic parameters of the digit in a cohort population of Amiata donkeys
}

\author{
Irene Nocera ${ }^{1 *}$, Benedetta Aliboni ${ }^{1}$, Caterina Puccinelli ${ }^{1}$, Giulia Pietrini ${ }^{2}$, Micaela Sgorbini ${ }^{1}$, \\ Simonetta Citi $^{1}$ and Giorgio Ricardi ${ }^{3}$ \\ ${ }^{1}$ Department of Veterinary Sciences, Veterinary Teaching Hospital “Mario Modenato”, Via Livornese snc, \\ San Piero A Grado PI, Italy \\ ${ }^{2}$ Private Practitioner, Torino, Italy \\ ${ }^{3}$ Donnington Grove Veterinary Group, Newbury, UK
}

\begin{abstract}
Background: The most common musculoskeletal conditions reported in donkeys are related to the foot. Radiographic examinations are clinically important in the diagnosis of foot abnormalities and are commonly used. However, few studies have been conducted to establish the normal radiographic appearance of a donkey's foot.

Aim: To determine the radiographic features of the front digit in healthy Amiata donkeys.

Methods: Radiographic examinations were performed on 56 forefeet of 28 Amiata donkeys. Three radiographic views of each front foot were taken: lateromedial, dorsopalmar and dorso- $65^{\circ}$ proximal/palmarodistal oblique. Seventeen angular and linear radiographic parameters and the crena solearis were evaluated in all forefeet, and 18 morphometric parameters were evaluated in 16 out of 56 forefeet. Statistical analysis was carried out on all the measures assessed. Results: The radiographic appearance of the forefoot was ascertained, and data were reported as median \pm standard error, minimum and maximum values. No statistical differences were obtained between the right and left forefeet.

Conclusion: The normal baseline parameters of the forefeet of Amiata donkeys were recorded and described and compared with other donkey breeds and horses. The findings highlighted that the donkey breed affects the radiographic parameters of the digit.
\end{abstract}

Keywords: Amiata, Donkey, Foot, Radiography.

\section{Introduction}

Donkeys (Equus Asinus) represent an important percentage of the world's equine population (Walker et al., 1995) and have been close companions for humans for millennia. Donkeys contribute to the agricultural economy as working animals or for transportation (Thiemann and Poore, 2019). Donkeys are used for milk production (Carroccio et al., 2000; Muraro et al., 2002) and in animal-assisted therapy (Borioni et al., 2012). They are important for the tourist industry and recently have become popular as pets (Thiemann and Rickards, 2013; El-Shafaey et al., 2017; Salem et al., 2018). The scientific literature has shown increased interest in their welfare (Rota et al., 2018), in donkeys' infectious diseases (Laus et al., 2015; Barrandeguy and Carossino, 2018; Sgorbini et al., 2018), alternative therapies (Bonelli et al., 2016a), and in specific diagnostic criteria and reference values in adults (Meucci et al., 2015; Sgorbini et al., 2017; Bonelli et al., 2019), pregnant and lactating jennies (Crisci et al., 2014; Bonelli et al., 2016b; Carluccio et al., 2016), and donkey foals (Sgorbini et al., 2013; Veronesi et al., 2014; Carluccio et al., 2017).
Musculoskeletal disease has also been investigated. Up to $65 \%$ of the donkey population may be affected by hoof-related problems (Mendoza et al., 2018; Thiemann and Poore, 2019). In a post-mortem study, Morrow et al. (2011) found that $44.8 \%$ of the donkey population investigated presented foot disorders, and $2.6 \%$ were euthanized due to irreversible damage of the foot. In most cases, foot disease was related mainly to hoof neglect and improper management (Thiemann and Poore, 2019). The most common clinical conditions reported were overlong hooves, unbalanced feet, solar abscesses, white line disease, laminitis, keratomas, and third phalange fractures (Thiemann and Rickards, 2013; Reix et al., 2014; Thiemann and Poore, 2019). In donkeys, the foot represents the same general anatomical structure as horses, but has particular morphological features related to keeping the hoof moist (Van Thielen et al., 2018) and enabling the donkeys to be safe on rough ground (Thiemann and Poore, 2019). Donkeys' feet are more vertical than horses $\left(5^{\circ}-10^{\circ}\right.$ more upright) and the hoof capsule is cylindrical in the dorsal view compared with the conical view of the horse (Fowler, 1995; Thiemann and Rickards, 2013; Thiemann and Poore, 2019). The heels are narrower,

*Corresponding Author: Irene Nocera. Via Livornese snc, San Piero a Grado PI, Italy. Email: irene.nocera@vet.unipi.it 
giving an overall U-shape to the sole (Fowler, 1995; Thiemann and Rickards, 2013).

Although radiography is commonly used to assess the severity of foot abnormalities (Salem et al., 2018), few studies have investigated the radiographic anatomy of normal donkey feet to provide univocal radiographic parameters (Collins et al., 2011; El-Shafaey et al., 2017). There has been a tendency to diagnose foot disease in donkeys using the same interpretation as horses (Cripps and Eustace, 1999). Since donkey feet are anatomically different from horse feet, the radiological parameters studied in horses cannot be used in donkeys (Thiemann and Poore, 2019). Moreover, there is a great variability in body size among different donkey breeds, which could cause significant variations in skeletal and hoof structures (Collins et al., 2011; El-Shafaey et al., 2017). This study aimed to establish the radiometric and morphometric parameters of a normal foot in Amiata donkeys in a homogeneous cohort in terms of sex, and to analyze the differences with horses.

\section{Materials and Methods}

\section{Animals}

A total of 28 Amiata female donkeys belonging to the Regional Stud Centre of Tuscany were enrolled in this study.

Donkeys were aged between 1 and 19 years (median age 16 years) and the body weight (BW) ranged between 110 and $393 \mathrm{~kg}$ (median $284 \mathrm{~kg}$ ). All jennies were at pasture, not in work, and were used for reproductive purposes. Jennies were housed in collective paddocks 24 hours a day, fed hay ad libitum along with commercial equine feed according to NRC energy recommendations (National Research Council, 2007). All jennies were barefoot and underwent an orthopedic examination to rule out lameness and/or malformations of the hoof before enrolment in the study.

\section{Radiographic protocol}

For all donkeys, the feet were trimmed no more than a week prior to carrying out the radiographic exam (Collins et al., 2011; El-Shafaey et al., 2017). All feet were thoroughly cleaned prior to radiography and the donkeys were put in a stock. All subjects were sedated with xylazine $(0.5 \mathrm{mg} / \mathrm{kg})$. The dorsal hoof wall was marked with a soft metal marker positioned at the palpable limit of the hoof wall (Collins et al., 2011; ElShafaey et al., 2017) in order to highlight the dorsal aspect and proximal limit of the hoof wall (Collins et al., 2011).

For all feet, lateromedial (LM), dorsopalmar (DPa), and dorso65 $5^{\circ}$ proximal-palmarodistal oblique (DPrPaDi) views were acquired (Walker et al., 1995; Butler et al., 2017; El-Shafaey et al., 2017). For LM and DPa views, both feet were positioned bearing the weight on a flat wooden block (4 cm high) to ensure an even weight distribution between the front limbs (Collins et al., 2011). For the DPrPaDi view, the feet were positioned on a Hickman block.
All radiographs were obtained with a focal distance of $80 \mathrm{~cm}$ (Butler et al., 2017). The radiographic beam was focused $1 \mathrm{~cm}$ below the coronary band for LM and DPa views (Collins et al., 2011), and midway between the coronary band and the tip of the hoof for the DPrPaDi view. The X-ray beam was perpendicular to the X-ray cassette and parallel to the ground. Exposure factors were $68 \mathrm{Kv}$ and $0.12 \mathrm{~mA} / \mathrm{s}$ for LM view; $70 \mathrm{Kv}$ and $0.12 \mathrm{~mA} / \mathrm{s}$ for DP view; and $74 \mathrm{Kv}$ and $0.12 \mathrm{~mA} / \mathrm{s}$ for $\mathrm{DPrPaDi}$ view. A portable $\mathrm{x}$-ray generator (GIERTH HF100 M) and an indirect digital radiographic system (Fujifilm FCR model Capsula X) were used. One experienced operator carried out all the radiographs (GP). Images were analyzed using a commercial software (Osirix DICOM Viewer, Pixmeo SARL, Switzerland), and all the radiographs were assessed by the same experienced operator (GP).

\section{Radiological parameters}

A series of 17 linear and angular, direct and derived radiometric parameters were evaluated in all 56 forefeet, for LM and DPa views (Fig. 1), according to the literature (Collins et al., 2011). A detailed description is given in Table 1. These parameters evaluate the anatomical relationship between the osseous structures of the foot, define their relationship with the hoof capsule, and characterize the morphometric appearance of the distal phalanx in a normal foot (Collins et al., 2011).

In addition, a total of 18 morphometric parameters were evaluated in 16 out of 56 forefeet for LM and DPa views (Fig. 2). A detailed description is given in Table 2.

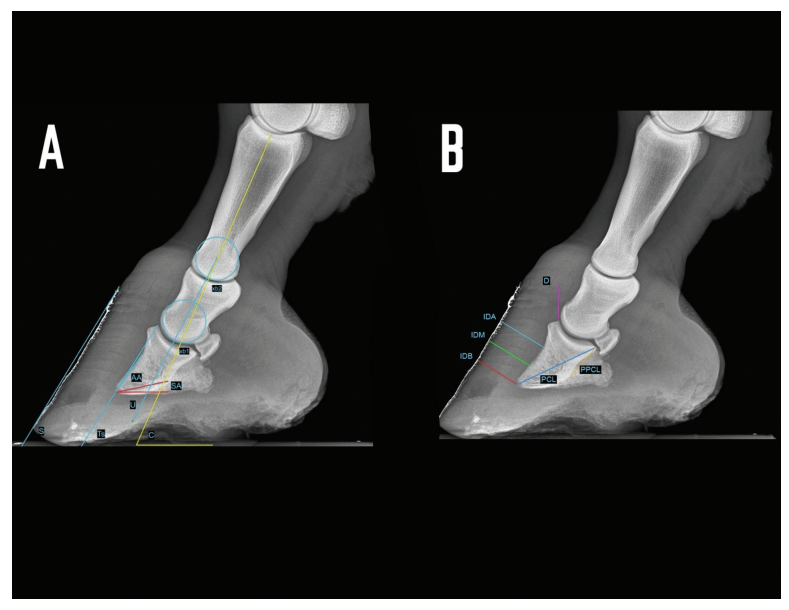

Fig. 1. LM radiographs of a normal donkey foot showing the angular (A) and linear (B) parameters established using Osirix DICOM Viewer (Pixmeo SARL, Switzerland). (A) Key: SA, angle of solar aspect of the distal phalanx. Ts, dorsal angle of the distal phalanx. AA. S, dorsal hoof wall angle. U, angle of proximal phalanx. C, angle of middle phalanx. Dorsal is to the left of image and palmar is to the right. (B) Key: IDA, integument depth (proximal site). IDM, integument depth (mid-dorsal site). IDB, integument depth (distal site). D, distal displacement of the distal phalanx. PCL, and PPCL. Dorsal is to the left of image and palmar is to the right. 
Table 1. Definition of linear and angular, direct, derived radiological foot parameters.

\begin{tabular}{|c|c|c|}
\hline \multicolumn{3}{|r|}{ Angular parameters of the foot } \\
\hline & Parameters & Anatomical definition \\
\hline 1 & S dorsal hoof wall angle & $\begin{array}{l}\text { Angle subtended between the aspect of the hoof wall and the ground line. Direct } \\
\text { parameter }\end{array}$ \\
\hline 2 & Ts dorsal angle of the distal phalanx & $\begin{array}{l}\text { Angle subtended between the dorsal aspect of the distal phalanx and the ground } \\
\text { line. Direct parameter }\end{array}$ \\
\hline 3 & $\mathrm{C}$ angle of middle phalanx & $\begin{array}{l}\text { Angle subtended between the long axis of the middle phalanx and the ground } \\
\text { line. Direct parameter }\end{array}$ \\
\hline 4 & U angle of proximal phalanx & $\begin{array}{l}\text { Angle subtended between the long axis of the proximal phalanx and the ground } \\
\text { line. Direct parameter }\end{array}$ \\
\hline 5 & $\begin{array}{l}\text { SA angle of solar aspect of the distal } \\
\text { phalanx }\end{array}$ & $\begin{array}{l}\text { Angle subtended between the solar aspect of the distal phalanx and the ground } \\
\text { line. Direct parameter }\end{array}$ \\
\hline 6 & Paxisangle of pastern axis & $\begin{array}{l}\text { Angular difference between long axis of the proximal phalanx and middle } \\
\text { phalanx. Derived parameter. Paxis = U-C }\end{array}$ \\
\hline 7 & HPA angle of hoof pastern axis & $\begin{array}{l}\text { Angular difference between the dorsal hoof wall angle and the long axis of the } \\
\text { proximal phalanx. Derived parameter. HPA = U-S. }\end{array}$ \\
\hline 8 & $\begin{array}{l}\text { Ang } \mathrm{H} \text { angular deviation between the } \\
\text { dorsal aspect of the DP and dorsum } \\
\text { of the hoof wall }\end{array}$ & $\begin{array}{l}\text { Angular difference between dorsal aspect of the distal phalanx and the dorsal hoof } \\
\text { wall angle-derived parameter. Ang } \mathrm{H}=\text { Ts-S. }\end{array}$ \\
\hline 9 & Ang R phalangeal rotation angle & $\begin{array}{l}\text { Angular difference between dorsal aspect of the distal phalanx and the long axis } \\
\text { of the proximal phalanx. Derived parameter. Ang } \mathrm{R}=\mathrm{U}-\mathrm{Ts} \text {. }\end{array}$ \\
\hline 10 & Ang FDIP rotation angle & $\begin{array}{l}\text { Angular difference between dorsal aspect of the distal phalanx and the long axis } \\
\text { of the middle phalanx. Derived parameter. Ang } \mathrm{F}=\mathrm{C}-\mathrm{Ts} \text {. }\end{array}$ \\
\hline 11 & $\mathrm{AA}$ & $\begin{array}{l}\text { Internal angle subtended between the distal palmar cortex and the dorsal aspect of } \\
\text { the distal phalanx. Direct parameter }\end{array}$ \\
\hline 12 & $\begin{array}{l}\text { IDA integument depth of the dorsal } \\
\text { aspect of the foot (proximal site) }\end{array}$ & $\begin{array}{l}\text { Perpendicular linear distance between the dorsal aspect of the hoof wall and the } \\
\text { dorsal surface of the distal phalanx, immediately distal to the distal limit of the } \\
\text { extensor process. Direct parameter }\end{array}$ \\
\hline 13 & $\begin{array}{l}\text { IDB integument depth of the dorsal } \\
\text { aspect of the foot (distal site) }\end{array}$ & $\begin{array}{l}\text { Perpendicular linear distance between the dorsal aspect of the hoof wall and the } \\
\text { dorsal surface of the distal phalanx proximal to the apex of the distal phalanx. } \\
\text { Direct parameter }\end{array}$ \\
\hline 14 & $\begin{array}{l}\text { IDM integument depth of the dorsal } \\
\text { aspect of the foot (mid-dorsal site) }\end{array}$ & $\begin{array}{l}\text { Perpendicular linear distance between the dorsal aspect of the hoof wall and the } \\
\text { dorsal surface of the distal phalanx at the midpoint between the IDA and IDB } \\
\text { measurement sites. Direct parameter }\end{array}$ \\
\hline 15 & D distal displacement of the distal phalanx & $\begin{array}{l}\text { Perpendicular linear distance between the proximal limit of the hoof wall and the } \\
\text { extensor process of the distal phalanx. Direct parameter }\end{array}$ \\
\hline 16 & PCL & $\begin{array}{l}\text { Linear distance between the apex of the distal phalanx and the articular process of } \\
\text { the navicular joint. Direct parameter }\end{array}$ \\
\hline 17 & PPCL & $\begin{array}{l}\text { Linear distance between the point of insertion of DDFT and the articular process } \\
\text { of the navicular joint. Direct parameter }\end{array}$ \\
\hline
\end{tabular}

Adapted from Collins et al. (2011).

Distal phalangeal rotation, if present, was measured by parameters SA, Ang H, Ang R, and Ang F. In addition to angular parameters, linear parameters were taken for the evaluation of the rotation of the phalanges.

The solar margin of the third phalanx was evaluated for semi-quantitative assessment in LM and DPrPaDi views, and a grading system scale was established, according to the literature (Walker et al., 1995; Butler et al., 2017) (Table 3).

\section{Statistical analysis}

The distribution of the radiological parameters was evaluated using the D'Agostino and Pearson's test. Since not all radiological parameters showed a Gaussian distribution, the distribution was considered as non-Gaussian. Thus, results were reported as median \pm standard error, minimum and maximum values. 


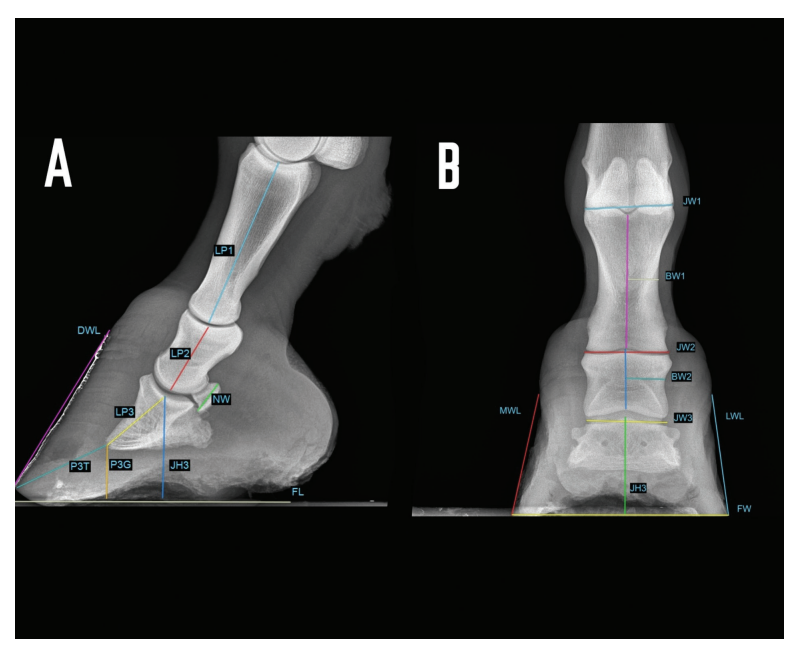

Fig. 2. LM (A) and dorsopalmar (B) radiographs of a normal donkey foot to show the morphometric parameters established using Osirix DICOM Viewer (Pixmeo SARL, Switzerland). (A) Key: LP1, length of first phalanx. LP2. LP3. JH3, height of the distal interphalangeal joint. NW, width of the navicular bone. FL. DWL. P3T. P3G. Dorsal is to the left of image and palmar is to the right. (B) Key: JW1, JW2, JW3, BW1, BW2, and JH3. Dorsopalmar radiographic view. MWL, medial wall length, LWL, FW, width of the foot. Medial is to the left of image and lateral is to the right.

The Mann-Whitney test was used for all the parameters measured to verify differences between right and left feet. Statistical significance was set at $p<0.05$.

Statistical analysis was carried out using GraphPad Prism 8.0 for Mac OS (GraphPad Software Inc., San Diego, CA).

\section{Ethical approval}

The present study was authorized by "Ethical Committee of the University of Pisa (23/19), according to the D.L.116/92 and D. Lgs. 26/14; owner written consents were obtained.

\section{Results}

Radiographs were carried out in all donkeys for a total of 56 feet. The time needed to carry out the radiographic exam ranged between 30 and 40 minutes, starting from the inoculation of the sedative. No statistical differences were found between the right and left feet for any of the parameters. The results for linear and angular parameters obtained in 56 feet are reported in Tables 4 and 5, while the data on the morphometric parameters obtained in 16 out of 56 feet are reported in Table 6. In the DPrPaDi view, the crena solearis of the distal phalanx appeared with a semi-circular shape, except for 3 out of $56(5.3 \%)$ feet that presented a crena solearis with grade 1 and 2 two out of $56(3.5 \%)$ feet with grade 2 .
In the LM view, periosteal-like bony proliferative changes occurred in 4 four out of $56(7.1 \%)$ feet with grade 2 and 3 three out of $56(5.3 \%)$ feet with grade 1 .

\section{Discussion}

Donkeys have particular anatomical and, as a consequence, radiographic features of the digit (Collins et al., 2011; El-Shafaey et al., 2017; Thiemann and Poore, 2019), which differ from those reported for horses (Thiemann and Rickards, 2013). We assessed the radiometric and morphometric parameters of normal feet in a population of Amiata female donkeys and analyzed the differences with other donkey breeds and horses.

In our study, a wide range of both $\mathrm{S}$ and Ts angular parameters was found, in agreement with Collins et al. (2011) for European donkeys. The median values obtained for S and Ts parameters were similar, supporting the hypothesis that the hoof wall and the dorsal aspect of the distal phalanx are mostly in parallel alignment in healthy donkey feet, with a minimal difference in inclination $\left(0.7^{\circ}\right)$ (Collins et al., 2011). The hypothesis of the parallel alignment was also supported by the median values of the linear parameters, IDA, IDM and IDB, which were comparable.

The distance between the dorsal hoof wall and the dorsal surface of the distal phalanx seems to vary according to the donkey breed. In fact, Collins et al. (2011) reported a mean IDM value of $15.6 \pm 2.6 \mathrm{~mm}$ (s.d.) in European donkeys, while in the Mammoth breed, an IDM value of $23 \pm 3 \mathrm{~mm}$ (s.d.) has been reported (Walker et al., 1995).

We found that the Amiata breed showed an intermediate IDM value $(21.2 \pm 0.6 \mathrm{~mm})$ between the two intervals proposed by other studies (Walker et al., 1995; Collins et al., 2011), in particular smaller than the Mammoth and bigger than European donkey breeds. This difference might be related to the body size. In fact, larger donkeys (i.e., Mammoth) presented higher values than smaller ones (i.e., Amiata and European), as suggested by other studies (Collins et al., 2011; Smith, 2016).

In our study, the median value of the linear distance (D) was shorter than the values reported in Egyptian donkeys (25.2 $\pm 31.8 \mathrm{~mm})$ (El-Shafaey et al., 2017), but longer $(10.4 \pm 3.7 \mathrm{~mm})$ than that reported in European donkeys (Collins et al., 2011).

In our study, the foot showed a broken forward pastern axis, similar to findings previously reported for European donkey breeds $\left(5.1^{\circ} \pm 5.2^{\circ}\right)$ (Collins et al., 2011). Amiata donkeys presented a wide range in values related to the third phalanx rotation degree (i.e., Ang R; Ang F; SA), which is in line with the results on European donkey breeds (Collins et al., 2011).

The data obtained in this study for the third phalanx angular morphometric features [i.e., palmar cortex length (PCL), proximal palmar cortex length (PPCL), apex angle (AA)] were in agreement with values 
Table 2. Morphometric parameters definitions of digital bones and hoof capsule.

\begin{tabular}{|c|c|c|}
\hline \multicolumn{3}{|r|}{ Morphometric parameters of the foot } \\
\hline & Parameters & Anatomical definition \\
\hline 1 & LP1, Length of first phalanx & $\begin{array}{l}\text { Longitudinal length of the first digital bone. Direct parameter, measured from the lateromedial } \\
\text { radiographic view. }\end{array}$ \\
\hline 2 & LP2 & $\begin{array}{l}\text { Longitudinal length of the second digital bone. Direct parameter, measured from the } \\
\text { lateromedial radiographic view. }\end{array}$ \\
\hline 3 & LP3 & $\begin{array}{l}\text { Longitudinal length of the third digital bone. Direct parameter, measured from the lateromedial } \\
\text { radiographic view. }\end{array}$ \\
\hline 4 & $\begin{array}{l}\text { NW, Width of the } \\
\text { Navicular bone }\end{array}$ & $\begin{array}{l}\text { Width of the navicular bone. Direct parameter, measured from the lateromedial radiographic } \\
\text { view. }\end{array}$ \\
\hline 5 & P3G & $\begin{array}{l}\text { Perpendicular linear distance between the tip of the third digital bone to the ground. Direct } \\
\text { parameter, measured from the lateromedial radiographic view. }\end{array}$ \\
\hline 6 & P3T & $\begin{array}{l}\text { Linear distance between the tip of the third digital bone to the toe, parallel to the ground. Direct } \\
\text { parameter, measured from the lateromedial radiographic view. }\end{array}$ \\
\hline 7 & JH3 & $\begin{array}{l}\text { Perpendicular linear distance between the distal interphalangeal joint to the ground. Direct } \\
\text { parameter, measured from the lateromedial radiographic view. }\end{array}$ \\
\hline 8 & FL & Length of the foot. Direct parameter, measured from the lateromedial radiographic view. \\
\hline 9 & DWL & $\begin{array}{l}\text { Length of the dorsal wall of the hoof from the coronary band to the ground. Direct parameter, } \\
\text { measured from the lateromedial radiographic view. }\end{array}$ \\
\hline 10 & JW1 & $\begin{array}{l}\text { Width of the metacarpophalangeal joint. Direct parameter, measured from the dorsopalmar } \\
\text { radiographic view. }\end{array}$ \\
\hline 11 & JW2 & $\begin{array}{l}\text { Width of the proximal interphalangeal joint. Direct parameter, measured from the dorsopalmar } \\
\text { radiographic view. }\end{array}$ \\
\hline 12 & JW3 & $\begin{array}{l}\text { Width of the distal interphalangeal joint. Direct parameter, measured from the dorsopalmar } \\
\text { radiographic view. }\end{array}$ \\
\hline 13 & BW1 & $\begin{array}{l}\text { Width of the first digital bone, measured from the point of lesser width, from the sagittal bone } \\
\text { plane to the bone cortex. Direct parameter, measured from the dorsopalmar radiographic view. }\end{array}$ \\
\hline 14 & BW2 & $\begin{array}{l}\text { Width of the second digital bone, measured from the point of lesser width, from the sagittal } \\
\text { bone plane to the bone cortex. Direct parameter, measured from the dorsopalmar radiographic } \\
\text { view. }\end{array}$ \\
\hline 15 & LWL & $\begin{array}{l}\text { Length of the lateral wall of the hoof, from the coronary band to the ground. Direct parameter, } \\
\text { measured from the dorsopalmar radiographic view. }\end{array}$ \\
\hline 16 & MWL, Medial wall length & $\begin{array}{l}\text { Length of the medial wall of the hoof, from the coronary band to the ground. Direct parameter, } \\
\text { measured from the dorsopalmar radiographic view. }\end{array}$ \\
\hline 17 & FW, Width of the foot & Width of the foot. Direct parameter, measured from the dorsopalmar radiographic view. \\
\hline 18 & $\begin{array}{l}\mathrm{JH} 3(\mathrm{DPv}) \text {. Dorsopalmar } \\
\text { radiographic view. }\end{array}$ & $\begin{array}{l}\text { Perpendicular linear distance between the distal interphalangeal joint to the ground. Direct } \\
\text { parameter, measured from the dorsopalmar radiographic view. }\end{array}$ \\
\hline
\end{tabular}

Adapted from El-Shafaey et al. (2017) (modified).

Table 3. Grading of the edge shape and periosteal proliferation of the distal phalanx.

\begin{tabular}{lll}
\hline & DPrPaDio view & LM view \\
\hline Grade 0 & Semi-circular edge of distal phalanx & Absence of periosteal proliferation \\
Grade 1 & Mild sagittal irregular shape on the edge & Mild periosteal proliferation \\
Grade 2 & Moderate irregular shape on the edge & Moderate periosteal proliferation \\
Grade 3 & Marked irregular shape on the edge & Marked periosteal proliferation \\
\hline
\end{tabular}

Adapted from Walker et al. (1995) and Butler et al. (2017) (modified). 
Table 4. Linear parameters results (expressed in $\mathrm{mm}$ ) in all 56 healthy forefeet.

\begin{tabular}{lcccccc}
\hline & IDA & IDB & IDM & D & PCL & PPCL \\
\hline $\mathrm{Med} \pm \mathrm{SE}$ & $19.0 \pm 0.6$ & $21.4 \pm 0.7$ & $21.2 \pm 0.6$ & $19.0 \pm 0.8$ & $43.4 \pm 0.4$ & $15.0 \pm 0.8$ \\
$\mathrm{~m}-\mathrm{M}$ & $14.0-24.0$ & $12.0-26.0$ & $15.0-25.0$ & $12.0-25.0$ & $36.0-47.0$ & $12.0-17.0$ \\
\hline
\end{tabular}

(Med): median value; (SE): standard error; $(\mathrm{m})$ : minimum value; $(\mathrm{M})$ : maximum value.

Table 5. Angular parameters results (expressed in degree) in all 56 healthy forefeet.

\begin{tabular}{lccccccccccc}
\hline & S & Ts & U & C & PAxis & HPA & AngH & AngR & AngF & SA & AA \\
\hline $\mathrm{Med} \pm$ SE & $57.3 \pm 0.7$ & $58 \pm 1.0$ & $63.8 \pm 0.9$ & $62.2 \pm 1.0$ & $9.0 \pm 0.9$ & $8.1 \pm 1.1$ & $1.4 \pm 0.8$ & $5.3 \pm 1.5$ & $-1.5 \pm 1.1$ & $9.0 \pm 0.5$ & $51.0 \pm 0.8$ \\
$\mathrm{~m}-\mathrm{M}$ & $44.2-68.6$ & $41.6-66.3$ & $48.3-80.8$ & $41.8-68.7$ & $-3.1-17.8$ & $-13.4-29.3$ & $-9.2-8.3$ & $-18.0-29.2$ & $-18.5-19.9$ & $2.6-16.1$ & $21.7-57.0$ \\
\hline
\end{tabular}

(Med): median value; (SE): standard error; $(\mathrm{m})$ : minimum value; $(\mathrm{M})$ : maximum value.

Table 6. Morphometric parameters results (expressed in $\mathrm{mm}$ ) in 16 out of 56 healthy forefeet.

\begin{tabular}{|c|c|c|c|c|c|c|c|c|c|}
\hline \multicolumn{10}{|c|}{ LM radiographic view } \\
\hline & LP1 & LP2 & LP3 & NW & P3G & P3T & JH3 & FL & DWL \\
\hline $\mathrm{Med} \pm \mathrm{SE}$ & $82.9 \pm 1$ & $35.3 \pm 0.5$ & $35.6 \pm 0.7$ & $16.4 \pm 0.5$ & $18.7 \pm 1.1$ & $27.5 \pm 1.3$ & $45.4 \pm 1.2$ & $127.5 \pm 3.4$ & $80.0 \pm 2.7$ \\
\hline $\mathrm{m}-\mathrm{M}$ & $77.0-93.1$ & $32.6-39.7$ & $32.1-41.1$ & $12.1-17.8$ & $14.2-28.1$ & $21.7-38.5$ & $41.0-56.3$ & $110.0-160.0$ & $70.0-105.0$ \\
\hline \multicolumn{10}{|c|}{ DPa radiographic view } \\
\hline & JW1 & JW2 & JW3 & BW1 & BW2 & LWL & MWL & FW & JH3 (DPv) \\
\hline $\mathrm{Med} \pm \mathrm{SE}$ & $46.5 \pm 0.6$ & $43.2 \pm 0.7$ & $42.2 \pm 0.7$ & $15.8 \pm 0.3$ & $20.5 \pm 0.2$ & $72.5 \pm 1.1$ & $65.0 \pm 1.2$ & $100 \pm 1.3$ & $50.1 \pm 1$ \\
\hline $\mathrm{m}-\mathrm{M}$ & $44.5-51.8$ & $40.6-50.0$ & $39.1-47.2$ & $13.3-18.2$ & $19.0-22.2$ & $60.0-80.0$ & $65.0-75.0$ & $90-110$ & $45.6-59.1$ \\
\hline
\end{tabular}

(Med): median value; (SE): standard error; $(\mathrm{m})$ : minimum value; $(\mathrm{M})$ : maximum value.

reported in European donkey breeds (Collins et al., 2011).

All the linear morphometric parameters measured in the Amiata donkey population showed higher values than Egyptian donkey breeds (El-Shafaey et al., 2017). The anatomical variation might be related to the body size (BW, height, and weight) of the Amiata donkey compared to Egyptian donkeys. In particular, the BW range in Amiata donkeys was higher than previously reported (El-Shafaey et al., 2017).

Comparing our findings with normal foot values reported for horses, many differences were observed. In particular, in horses, the $\mathrm{S}$ and $\mathrm{Ts}$ values showed a narrow range of values (i.e., $48.2^{\circ} \pm 2.6^{\circ}$ and $47.8^{\circ} \pm$ $3^{\circ}$, respectively) and less variability among different breeds (Linford et al., 1993), compared to our results for donkeys.

In horses, homogenous IDM values were found between different breeds (i.e., Hanoverian: $18 \pm 0.7$ mm; Thoroughbred: $16.3 \pm 1.8 \mathrm{~mm}$; other breeds: 18.4 $\pm 1.4 \mathrm{~mm}$; ponies: $13.2 \pm 1.9 \mathrm{~mm}$ ) (Cripps and Eustace, 1999). In our donkeys, these values were generally higher, supporting the hypothesis of a thicker hoof wall and, as a consequence, a deeper location of the third phalanx within the hoof in donkeys compared to horses, as previously suggested (Collins et al., 2011). In horses, the $D$ value, also called the founder distance, has a wider variability $(-2-10 \mathrm{~mm})$ (Parks and
Belknap, 2017) compared to donkey breeds. However, the $D$ value in horses is smaller than in donkeys. The $D$ value is relevant in the clinical evaluation of laminitis in horses and a value over $8 \mathrm{~mm}$ is considered diagnostic for laminitis in Thoroughbreds (Cripps and Eustace, 1999). In donkeys, the distal dislocation of the third phalanx should therefore be evaluated carefully, bearing in mind that the bone is usually located deeper in the hoof capsule (Collins et al., 2011; El-Shafaey et al., 2017; Thiemann and Poore, 2019).

Another difference between horses and donkeys was found in the SA value, which showed a narrow range and smaller values in horses (Parks and Belknap, 2017) compared with donkeys. The reported value for Warmblood horses is $4.0^{\circ} \pm 2.1^{\circ}$ and for ponies $6.3^{\circ} \pm$ $2.6^{\circ}$ (Parks and Belknap, 2017), while in the present study the value was $9.0^{\circ} \pm 0.5^{\circ}$.

It has been suggested that in horses, the SA value is useful for the diagnosis and prognosis of laminitis, and the degree of rotation is inversely related to the prognosis (Linford et al., 1993). Conversely, our findings support the hypothesis that the SA value may provide limited information on the third phalanx rotation in donkeys, in agreement with previous reports (Collins et al., 2011). The SA value should therefore be assessed in relation with other relevant radiographic values for the diagnosis of laminitis, such as S, Ts, Ang H, Ang R, Ang F, IDM, and D (Collins et al., 2011). 
In the present study, an irregular dorsal solar margin and changes in the periosteal-like bony proliferation on the mid-dorsal aspect of the distal phalanx were observed with a low prevalence $(7.1 \%$ of the feet with grade 2 and $5.3 \%$ of the feet with grade 1) and were not associated with signs of lameness. Our results are in contrast with findings reported in horses and in another study conducted on donkeys (Linford et al., 1993; Walker et al., 1995). In Thoroughbreds, in race training, the bony proliferation on the distal phalanx is frequently seen in sound horses $(88 \%)$, and seems to be related to the age of the first race (Linford et al., 1993). The bony proliferation was also verified in $75 \%$ of Mammoth donkeys (Walker et al., 1995). In addition, a high variability of the dorsal solar margin shape not associated with signs of lameness was observed in Mammoth donkeys (87.5\%) (Walker et al., 1995). These differences might be explained considering the athletic activities of horses compared to the low level of activity in our donkey population (Linford et al., 1993). Finally, in donkeys, bone morphometric parameters [i.e., length of second phalanx (LP2), length of third phalanx (LP3), width of the metacarpophalangeal joint (JW1), width of the proximal interphalangeal joint (JW2), width of the distal interphalangeal joint (JW3), width of the first phalanx (BW1), and width of the second phalanx (BW2)] showed lower values than horses, while hoof capsule parameters [i.e., tip of P3 to the ground (P3G), tip of $\mathrm{P} 3$ to the toe (P3T), height of the distal interphalangeal joint (JH3), length of the foot (FL), length of the dorsal wall (DWL), lateral wall length (LWL), and medial wall length (MWL)] had similar values (Rocha et al., 2004). As discussed previously, this anatomical variation might be related to the different body sizes between donkeys and horses. In the present study, the crena solearis generally presented (51 out of 56,91\%) a semi-circular shape, and was altered in 5 five out of $56(9 \%)$ donkeys. Walker et al. (1995) reported a great variability in the shape of the crena solearis and were not able to exactly define the normal appearance; also, in horses, a variable size and appearance of the crena has been found (Butler et al., 2017). These results would seem to confirm the relevance of differences in breed regarding hoof and bone features.

Our study highlighted the great variability in bone and hoof parameters between different donkey breeds, which also indicates the importance of obtaining parameters for each breed.

The limitations of this study concern the small number of donkeys enrolled and the inclusion of only females. As reported in the literature, the wither height and weight of female Amiata donkeys do not differ significantly from males or geldings (Casini et al., 2007; Cecchi et al., 2007). It is thus possible that the weight and height in Amiata donkeys might not lead to differences in morphometric hoof parameters between females and males. On the other hand, our study provided results from data only from female donkeys and this could potentially create a bias when comparing pathological findings with reference ranges. However, a larger study group, including males and geldings, would provide more accurate data for the assessment of a normal radiographic appearance of the fore digit in Amiata donkeys.

Our data confirm that the donkey has a unique radiological anatomy, as also suggested by others (Collins et al., 2011; El-Shafaey et al., 2017). This study contributes to the literature by developing a specific model and by collecting data on healthy feet of Amiata donkeys. Prior knowledge of these parameters is essential for the early detection of slight anatomical modifications of the digit and hoof shape (El-Shafaey et al., 2017; Thiemann and Poore, 2019). We also confirm that the donkey breed affects the variability in the radiographic parameters of the digit, which is in agreement with studies conducted by Walker et al. (1995) and Collins et al. (2011) on Mammoth and European donkey breeds, respectively.

\section{Acknowledgment}

We are grateful to the "Ente Terre Regionali Toscane" stud farm (Tuscany, Italy) for allowing us to use the animals in this study.

\section{Conflict of interest}

The authors declare that there is no conflict of interest. Authors' contributions

GR, MS, and SC conceived, designed, and supervised the project. IN, BA, and GP executed the experiment. IN, BA, GP, and CP analyzed the data. All the authors interpreted the data, wrote, and critically revised the manuscript for intellectual content and approved the final version. IN and MS had full access to all the data in the study and take responsibility for the integrity of the data and the accuracy of the data analysis.

\section{References}

Barrandeguy, M.E. and Carossino, M. 2018. Infectious diseases in donkeys and mules: an overview and update. J. Equine Vet. Sci. 65, 98-105.

Bonelli, F., Busechian, S., Meucci, V., Caporrino, G., Briganti, A., Rueca, F., Zappulla, F., Ferini, E., Ghiandai, L. and Sgorbini M. 2016a. pHyloGASTRO in the treatment of Equine Gastric Ulcer lesions. J. Equine Vet. Sci. 46, 69-72.

Bonelli, F., Rota, A., Aurich, C., Ille, N., Camillo, F., Panzani, D. and Sgorbini, M. 2019. Determination of salivary cortisol in donkey stallions. J. Equine Vet. Sci. 77, 68-71.

Bonelli, F., Rota, A., Corazza, M., Serio, D. and Sgorbini, M. 2016b. Haematological and biochemical findings in pregnant, postfoaling and lactating jennies. Theriogenol. 85, 1233-1238.

Borioni, M., Marinaro, P., Celestini, S., Del Sole, F., Magro, R., Zoppi, D., Mattei, F., Dall'Armi, V., Mazzarella, F., Cesario, A. and Bonassi, S. 2012. Effect of equestrian therapy and onotherapy in 
physical and psycho-social performances of adults with intellectual disability: a preliminary study of evaluation tools based on the ICF classification. Disabil. Rehabil. 34, 279-297.

Butler, J.A., Colles, C.M., Dyson, S.J., Kold, S.E., Poulos, P.W. and Puchalski, S. 2017. The foot. In Clinical radiology of the horse, Eds., Butler, J.A., Colles, C.M., Dyson, S.J., Kold, S.E., Poulos, P.W. and Puchalski, S. 4th ed. Chichester, UK: John Wiley \& Sons, pp: $55-148$.

Carluccio, A., Contri, A., Gloria, A., Veronesi, M.C., Sfirro, M.P., Parrillo, S. and Robbe, D. 2017. Correlation between some arterial and venous blood gas parameters in healthy newborn Martina Franca donkey foals from birth to 96 hours of age. Theriogenology. 87, 173-178.

Carluccio, A., Noto, F., Parrillo, S., Contri, A., De Amicis, I., Gloria, A., Robbe, D. and Veronesi, M.C. 2016. Transrectal ultrasonographic evaluation of combined utero-placental thickness during the last half of pregnancy in Martina Franca donkeys. Theriogenology. 86, 2296-2301.

Carroccio, A., Cavataio, F. and Montalto, G. 2000. Intolerance to hydrolysed cow's milk proteins in infants: clinical characteristic and dietary treatment. Clin. Exp. Allergy. 30, 1597.

Casini, L., Sgorbini, M., Magni, L. and Corazza, M. 2007. Morphological evaluation of the Amiata donkey. Ippologia. 18, 33-35.

Cecchi, F., Ciampolini, R., Ciani, E., Mazzanti, E., Tancredi, M. and Presciuttini, S. 2007. Morphological characterization of the Amiata donkey breed through the data reported in the Anagraphic Register. Ital. J. Anim. Sci. 6(suppl 1), 70.

Collins, S.N., Dyson, S.J. and Murray, R.C. 2011. Radiological anatomy of the donkey foot: objective characterization of the normal and laminitic donkey foot. Equine Vet. J. 43, 478-486.

Cripps, P.J. and Eustace, R.A. 1999. Radiological measurements from the feet of normal horses with relevance to laminitis. Equine Vet. J. 31, 427-432.

Crisci, A., Rota, A., Panzani, D., Sgorbini, M., Ousey, J.C. and Camillo, F. 2014. Clinical, ultrasonographic, and endocrinological studies on donkey pregnancy. Theriogenology. 81, 275-283.

El-Shafaey, E.A., Salem, M.G., Mosbah, E. and Zaghloul, A.E. 2017. Morphometric evaluation of relevant radiographic parameters of the forefeet of clinically normal donkeys (Equus asinus). J. Hellenic Vet. Med. Soc. 68, 467-478.

Fowler, J. 1995. Trimming donkey feet. Equine Vet. Educ. 7, 18-21.

Laus, F., Spaterna, A., Faillace, V., Veronesi, F., Ravagnan, S., Beribe, F., Cerquetella, M., Meligrana, M. and Tesei, B. 2015. Clinical investigation on Theileria equi and Babesia caballi infections in donkeys from central Italy. BMC Vet. Res. $11,100$.

Linford, R.L., O'Brien, T.R. and Trout, D.R. 1993. Qualitative and morphometric radiopraphic finding in the distal phalanx and digital soft tissues of sound Thoroughbred racehorses. Am. J. Vet. Res. 54, 38-51.

Mendoza, F.J., Toribio, R.E. and Perez-Ecija, A. 2018. Donkey internal medicine- part II: cardiovascular, respiratory, neurologic, urinary, ophthalmic, dermatology, and musculoskeletal disorders. J. Equine Vet. Sci. 65, 86-97.

Meucci, V., Sgorbini, M., Bonelli, F., Corazza, M., Lippi, L., Intorre, L. and Grazia, G. 2015. Determination of glomerular filtration rate in adult horses and donkeys by single IV administration of Iohexol. J. Equine Vet. Sci. 35, 36-40.

Morrow, L.D., Smith, K.C., Piercy, R.J., Du Toit, N., Burden, F.A., Olmos, G., Gregory, N.G. and Verheyen, K.L.P. 2011. Retrospective analysis of post-mortem findings in 1,444 aged donkeys. J. Comp. Pathol. 144, 145-156.

Muraro, M.A., Giampietro, P.G. and Galli, E. 2002. Soy formulas and nonbovine milk. Ann. Allergy Asthma Immunol. 89, 97-101.

National Research Council. 2007. Donkeys and other equids. Nutrient requirements of horses. Washington DC: The National Academy Press.

Parks, A.H. and Belknap, J.K. 2017. Diagnostic imaging. In Equine laminitis. Eds., Belknap, J.K. and Geor, R. 1st ed. Ames, Iowa: Wiley Blackwell, pp: 226-239.

Reix, C., Burn, C.C., Pritchard, J.C., Barr, A.R.S. and Whay, H.R. 2014. The range and prevalence of clinical signs and conformation associated with lameness in working draught donkeys in Pakistan. Equine Vet. J. 46, 771-777.

Rocha, J.V., Lischer, C.J., Kummer, M., Hässig, M. and Auer, J.A. 2004. Evaluating the measuring software package Metron-PX for morphometric description of equine hoof radiographs. J. Equine Vet. Sci. 24, 347-354.

Rota, A., Sgorbini, M., Panzani, D., Bonelli, F., Baragli, P., Ille, N., Gatta, D., Sighieri, C., Casini, L., Maggiorelli, M.M., Aurich, C. and Camillo, F. 2018. Effect of housing system on reproductive behaviour and on some endocrinological and seminal parameters of donkey stallion. Reprod. Domest. Anim. 53, 40-47.

Salem, M., El-Shafaey, E.A., Mosbah, E. and Zaghloul, A. 2018. Ultrasonographic, computed tomographic and magnetic resonance imaging of the normal donkeys (Equus asinus) digit. J. Equine Vet. Sci. $74,68-83$.

Sgorbini, M., Bonelli, F., Papini, R., Busechian, S., Briganti, A., Laus, F., Faillace, V., Zappulla, F., Rizk, A. and Rueca, F. 2017. Equine gastric ulcer syndrome in adult donkeys: investigation on 
prevalence, anatomical distribution and severity. Equine Vet. Educ. 30, 206-210.

Sgorbini, M., Bonelli, F., Rota, A., Baragli, P., Marchetti, V. and Corazza, M. 2013. Hematology and clinical chemistry in Amiata donkey foals from birth to 2 months of age. J. Equine Vet. Sci. 33, 35-39.

Sgorbini, M., Veronesi, F., Fratini, M. and Laus, F. 2018. Tick-borne diseases and gastric ulcer in the donkey. J. Equine Vet. Sci. 65, 62-65.

Smith, D.C. 2016. The book of donkeys: a guide to selecting, caring, and training. Rowman \& Littlefield, Globe Pequot/Lyons Press, Louisville, CO.

Thiemann, A.K. and Poore, L.A. 2019. Hoof disorders and farriery in the donkey. Vet. Clin. North Am. Equine Pract. 35, 643-658.

Thiemann, A.K. and Rickards, K. 2013. Donkey hoof disorders and their treatment. In Pract. 35, 134-140.
Van Thielen, B., Willekens, I., Van der Schicht, A., Pestieau, P., Verhelle, F., Goossens, P., Decoster, R., Jacqmot, O., Delperdange, P., Busoni, V., De Mol, G., Buls, N., Provyn, S., Kichouh, M., de Mey, J. and Murray, R. 2018. Radiography of the distal extremity of the manus in the donkey foal: normal images and quantitative characterization from birth to 2 years of age: a pilot study. Anat. Histol. Embryol. 47, 71-83.

Veronesi, M.C., Gloria, A., Panzani, S., Sfirro, M.P., Carluccio, A. and Contri, A. 2014. Blood analysis in newborn donkeys: hematology, biochemistry, and blood gases analysis. Theriogenol. 82, 294-303.

Walker, M., Taylor, T.S., Slater, M., Hood, D., Weir, V. and Elslander, J. 1995. Radiographic appearance of the feet of mammoth donkeys and the findings of subclinical laminitis. Vet. Radiol. Ultrasound. 35, 32-37. 